\title{
"Sarados" e "gostosas" entre alguns outros: aspectos da educação de corpos masculinos e femininos em academias de ginástica e musculação ${ }^{1}$
}

Roger Hansen Alexandre Fernandez Vaz

Resumo: Este estudo apresenta resultados de uma pesquisa desenvolvida durante seis meses em duas academias de ginástica e musculação localizadas em Florianópolis. As investigações - norteadas pelo fenômeno contemporâneo do culto do corpo - mostram que a corrida ascética pela forma física idealizada envolve a louvação/desprezo de certas regiões corporais, além de fronteiras simbólicas e materiais que influenciam homens e mulheres na escoIha de diferentes práticas. Assim, liga-se ao gênero a geografia destes espaços e as diferenças nas hierarquias pautadas na imagem corporal. Os resultados apontam para a fluidez das relações humanas e fazem pensar em um possível eclipse do sujeito.

Palavras-chave: Corpo. Gênero. Subjetividade. Culto ao Corpo. Indústria Cultural.

\section{Prólogo}

As academias de ginástica e musculação conjugam-se com um vasto repertório de práticas e técnicas que contemporaneamente se acercam e produzem o corpo de mulheres e homens, seja na sua materialidade que cruza natureza e cultura ou ainda, se assim se preferir, no conjunto de representações que sobre esses corpos incide. As academias podem ser entendidas como centros de culto a este

${ }^{1}$ A investigação faz parte do projeto integrado Teoria Crítica, Racionalidades e Educação, inanciado pelo CNPq (Bolsas de Produtividade em Pesquisa, Mestrado, Iniciação Científica e Iniciação Científica Júnior; Auxílio Pesquisa) e pela FAPESC (Auxílio Pesquisa). Os autores agradecem o apoio, fundamental para a realização do projeto. Versões anteriores desse trabalho foram apresentadas no Congresso Sul-brasileiro de Ciências do Esporte (Criciúma, CBCE/UNESC, 2004) e no VI Fazendo Gênero (Florianópolis, UFSC, 2004) Os autores agradecem aos/às pareceristas anônimos da Revista Movimento as sugestões apresentadas.

Movimento, Porto Alegre, v.12, n. 01, p. 133-152, janeiro/abril de 2006. 
objeto tão caro a nossa sociedade, locais onde se desenvolve toda uma cultura em que o corpo se torna uma intersecção na qual são engendrados vocabulários, códigos, rituais, costumes e estruturas hierárquicas que conferem um modo de agir e de ser peculiares e especificamente normatizados por dispositivos variáveis de geração, gênero, etnia, pertencimento de classe, entre outros.

Se o corpo sofre cuidados específicos na sociedade contemporânea - tanto como cruzamento privilegiado das sociedades disciplinares, quanto no registro algo "regrado" das sociedades de controle -, é nas academias que ele ganha centralidade máxima, quando homens e mulheres fazem-se em pedaços somáticos a serem investidos de modo específico, configurando um ambiente geograficamente estruturado de acordo com as regiões anatômicas sacralizadas pelas personagens que ali convivem, mas também pela grande massa que absorve o discurso hegemônico do culto do corpo ditado no contexto dos esquemas da indústria cultural. Pensamos aqui nas pessoas que consomem os programas televisivos com receitas de exercícios e dietas, assim como as revistas cujo objetivo é o mesmo, assim como as imagens dos e das modelos que admiramos nas novelas e nas fotos da imprensa especializada, entre tantos outros dispositivos da liturgia corporal.

Os resultados com os quais trabalhamos neste artigo são oriundos de uma investigação etnográfica ${ }^{2}$ em duas academias de ginástica e musculação localizadas em bairros centrais de Florianópolis. A pesquisa teve como objetivo entender como se materializam aspectos da indústria cultural - clássico conceito cunhado por Horkheimer e Adorno (1997) para tentar compreender os processos de transformação capitalista - sobre o corpo e suas expressões, entre eles as configurações de gênero, objeto privilegiado deste artigo. Interessava-nos saber como os proces-

${ }^{2}$ Freqüentamos as academias durante seis meses como alunos regulares, de modo que os dados foram coletados sistematicamente e registrados em cadernos de campo. No caso das entrevistas, em gravadores.

Movimento, Porto Alegre, v.12, n. 01, p. 133-152, janeiro/abril de 2006. 
sos que educam para configurações corporais masculinas e femininas se davam e se isso acontecia de forma semelhante em distintos contextos, se era possível aceitar um discurso generalizante sobre o culto ao corpo nas academias de ginástica e musculação.

As academias são espaços formais de educação e culto do corpo, distantes entre si aproximadamente três quilômetros e freqüientadas, como é comum nesses ambientes, por integrantes das camadas médias (VELHO, 1986; SABINO, 2000).

Denominamos as instituições respectivamente de Pequena e Grande Academia, adjetivos que remetem ao poderio estrutural que dispõem. No primeiro caso, trata-se de uma associação de funcionários públicos localizada dentro de uma grande repartição federal, sendo o espaço locado por um professor de Educação Física. A academia corresponde a uma pequena sala, com equipamentos simples e uma mensalidade bastante baixa, sem cobrança de matrícula.

Por sua vez, a Grande Academia constitui-se como um grande centro de Fitness, franquia de uma marca de renome internacional. $\mathrm{O}$ valor de sua mensalidade é três vezes superior ao da academia de menor porte que acima descrevemos. Conta com uma construção própria e peculiarmente planejada. Tanto sua estrutura material - emoldurada por equipamentos da mais alta tecnologia disponível no mercado - como sua organização administrativa e funcionamento impecáveis, regidos por planos profissionais elaborados por empresas especializadas, conformam um ambiente que contrasta fortemente com a outra instituição pesquisada.

Os sujeitos/atores da pesquisa ${ }^{3}$ foram selecionados a partir de quatro critérios básicos: Assiduidade; Faixa Etária; Prestígio social na academia; Constituição Física. Os professores de Edu-

${ }^{3}$ Foram realizadas 14 entrevistas. Dos informantes, 10 eram alunos e 4 professores. Ressaltamos, entretanto, que nem todos os entrevistados são citados no presente trabalho.

Movimento, Porto Alegre, v.12, n. 01, p. 133-152, janeiro/abril de 2006. 
cação Física, Instrutores/estagiários foram escolhidos de acordo com o gênero: dois homens e duas mulheres de cada local. Temos entre nossos entrevistados basicamente estudantes universitários, profissionais liberais e funcionários públicos A diversidade entre os sujeitos, sobretudo naquilo que remete aos seus respectivos lugares sociais, foi algo que procuramos priorizar. Nesse sentido, constituíram esse grupo desde um professor aposentado, de 56 anos e aparência "comum", aluno iniciante de musculação, até uma jovem estudante de pré-vestibular, considerada uma das meninas mais bonitas da academia, assídua há dez anos nas aulas de ginástica e musculação.

Nas próximas páginas apresentamos alguns detalhes das instituições pesquisadas, suas características marcantes e outros aspectos que permitem uma melhor compreensão de nosso objeto de estudo. Na sequiência apresentamos resultados da pesquisa que descrevem diferentes expectativas de homens e mulheres em relação à aparência corporal. Falamos da organização espacial, dos interesses de homens e mulheres que municiam os olhares e determinam os investimentos sobre os corpos em suas reafirmações do que se espera do masculino e do feminino. Fechamos o texto discutindo elementos dos processos de (des)subjetivação ${ }^{4}$ lá inseridos em algumas de suas nuanças, focando nossa atenção num possível processo de reificação.

Das Academias: "climas", espaços e consumo de corpos anatomizados

A Pequena Academia consiste em uma única sala de $362 \mathrm{~m}^{2}$, metade deles destinada à musculação e a outra à ginástica. Não há

${ }^{4}$ Referimo-nos aqui à ambigüidade constante na própria dinâmica social que não nos permite afirmar, segundo entendemos, se estamos diante de sempre novas formas de subjetivação mediadas pelos múltiplos dispositivos disciplinares e de controle, ou se a questão é outra, de simplesmente não haver mais, como sugere Adorno (1992), sujeito, de estarem suspensas suas possibilidades de efetivação.

Movimento, Porto Alegre, v.12, n. 01, p. 133-152, janeiro/abril de 2006. 
parede divisória, mas alguns aparelhos de musculação delimitam o espaço para cada atividade. A escassa quantidade de aparelhos e sua disposição de forma aleatória, deixando lacunas na sala, faz com que muitas vezes os freqüentadores reivindiquem as máquinas ao mesmo tempo, obrigando a um revezamento, o que proporciona um contato interpessoal maior, fator que possivelmente contribui para a socialização entre os alunos. Há um único espelho em toda a sala, importante para o deslocamento das pessoas pelo espaço, uma vez que a imagem que se deixa captar, a própria e a dos outros, é um fator determinante nas condutas.

O fato de a Pequena Academia ser constituída de uma sala única promove ainda uma situação peculiar. Observamos que ela adquire um novo "espírito" durante as aulas de ginástica, quando o espaço ganha um ar de festa. As pessoas desfilam, dançam ao som da música elevada, paqueram, olham-se atenciosamente e de maneira mais desinibida. O território firma-se como um ambiente de relações interpessoais, de conquista de novas amizades e, obviamente, de paquera e flerte, quando então o corpo adquire importância máxima como reduto dos atributos de sedução. Quando questionado sobre esse ponto um professor não hesitou: "Tem, assim, mas sempre o intermediário acaba sendo eu, sabe... pô, olha lá a gata, dá a idéia pra mim; mas rola, rola." (Tiago, professor estagiário) $)^{5}$.

Com enorme frequiência foi possível observar situações como essa, principalmente em relação aos homens, quando prendem fixamente o olhar em meninas que se exercitam em aparelhos como aqueles que permitem um movimento de afastar e unir as pernas, os em que as mulheres precisam deitar-se de bruços e, sobretudo, nas aulas de ginástica, especialmente as que envolvem um grande número de praticantes dançando com

${ }^{5} \mathrm{Na}$ procura da proteção aos depoentes, a quem muito agradecemos, todos os nomes citados são fictícios.

Movimento, Porto Alegre, v.12, n. 01, p. 133-152, janeiro/abril de 2006 
movimentos sensuais, como é o caso da aula de "Axé". As mulheres, por sua vez, também paqueram, mas, parecem ser mais discretas e cautelosas, como convém à dinâmica da sociedade patriarcal na qual são constituídas, ao menos imaginariamente, como presas.

A Grande Academia possui características muito singulares. Trata-se de um portentoso centro de fitness no qual os cuidados com os mais ínfimos detalhes são observados, como destacou um professor: "Anilhas em seu local, os dumbles em seus locais, as máquinas todas ajustadas, tudo certinho, tudo lubrificado." O fato da organização da academia ser feita por uma empresa especializada, a extrema organização dos espaços e das máquinas, que jamais mudam um centímetro sequer de lugar, a alta tecnologia empregada nos aparelhos, considerados os mais sofisticados do mercado, a limpeza impecável da sala, tudo isso confere ao ambiente uma sensação de assepsia e "perfeição".

Articula-se à ocupação geográfica das academias uma certa anatomização dos corpos. A distribuição dos aparelhos bem como sua própria constituição e finalidades fazem parte de uma organização que prima pela fragmentação corporal, fazendo com que cada região anatômica receba atenção específica. Dos corpos restritamente manipulados, fala-se em músculos peitorais, dorsais, bíceps, tríceps, entre outros. Mas, cada grupo muscular é ainda mais esquadrinhado, de modo que os peitorais, por exemplo, recebem exercícios para sua porção superior, inferior e média. As coxas e nádegas, por sua vez, são exercitadas em suas partes internas e externas, anterior (parte distal e proximal) e posterior. O corpo anatomizado deve ser percorrido em cada centímetro específico pelos mais diversos estímulos oferecidos por máquinas minuciosas em seus efeitos: "Ali tem uma máquina que trabalha esse músculo aqui ó [mostrando o músculo tibial anterior]...então, tem coisinhas assim que você nem imagina." (Dulce, funcionária da Grande Academia).

Movimento, Porto Alegre, v.12, n. 01, p. 133-152, janeiro/abril de 2006. 
Corpos "sarados" ou "comuns": a autoridade do corpo e suas hierarquias

Seguindo uma sugestão de Sabino (2002), analisamos a estrutura hierárquica no âmbito específico da musculação, onde cada indivíduo assume um determinado lugar social de acordo com a autoridade corporal que representa. Sabino destaca três personagens que cabem aos homens e também às mulheres, na seguinte ordem: os fisiculturistas, os veteranos e os comuns.

No que se refere à Grande Academia, vários aspectos ajudam a compor o ambiente que mescla estética, limpeza e performance. Dentre eles, há professores que trabalham na academia como personal trainers e que são também fisiculturistas profissionais. Eles chamam a atenção pela imensa camada de massa muscular que possuem. Estes personagens pertencem à categoria dos fisiculturistas, ícones masculinos pelo que poderíamos chamar de capital corporal e capital de competência. Por apresentarem um desenvolvimento muscular maximizado, e uma sapiência decorrente de anos de treinamento e do eventual uso de esteróides anabolizantes, acabam disputando a autoridade com os professores com formação universitária.

Há neste espaço também algumas mulheres fisiculturistas. Com aspecto considerado "masculinizado" e em número inferior, elas assumem uma aparência hipermusculosa. Todavia, seu prestígio com as pessoas do mesmo sexo não é equivalente ao dos homens da mesma categoria.

No ambiente da Grande Academia os fisiculturistas representam um papel muito importante. Por um lado são pontos de referência para os demais alunos e exemplos de sucesso na batalha por músculos hipertrofiados; por outro, conferem uma legitimidade especial ao espaço, exemplos de um ideal que se apresenta como possível, provas vivas de quão longe poderia chegar quem decide treinar naquele local.

Movimento, Porto Alegre, v.12, n. 01, p. 133-152, janeiro/abril de 2006 
Há também nesta academia muitas pessoas que se enquadram na categoria de veteranos. A ela pertencem aqueles que são considerados os possuidores dos corpos mais bonitos. Os homens são os "sarados" e as mulheres as "gostosas" da academia. Estas ocupam o posto mais alto da estrutura hierárquica feminina.

Desse modo, as academias adquirem características ritualísticas, já que os neófitos podem querer percorrer alguns anos de sacrifício para atingir o sonhado status de fisiculturista ou de veterano. Os treinamentos, as roupas, o trânsito na hierarquia, o vocabulário que passam a ter que dominar, os centímetros (e gordura) a menos ou (de músculos) a mais, tudo isso compõe o caminho para se chegar lá.

O vestuário dos alunos da Grande Academia é outro fator que impressiona. Todas as mulheres, independentemente da faixa etária, usam roupas próprias para ginástica. São roupas "modernas", muitas vezes de grifes famosas, sempre com cores vivas e variadas (roxo, amarelo, laranja, vermelho), e também muito justas e com costuras e decotes muito ousados e provocantes e que ressaltam certas partes do corpo como os seios, a barriga e as costas. As duas últimas são regiões que na maioria das vezes ficam quase totalmente à mostra.

Os homens das mais diversas faixas etárias usam bermudas, regatas e camisetas justas nos braços e no peito. Tanto homens quanto mulheres usam calçados novos. São modelos sofisticados, de marcas famosas, sempre limpos, que combinam com a aparência asséptica da academia.

Além destes detalhes do vestuário, há muitas pessoas bronzeadas, tatuadas, usando piercings e cortes de cabelos arrojados, compondo um figurino típico da cultura urbana na qual se inserem as práticas de modelagem corporal das academias.

Existe ainda um grande número de pessoas que levanta cargas elevadas nos exercícios. Este fator ajuda a compor o ambien-

Movimento, Porto Alegre, v.12, n. 01, p. 133-152, janeiro/abril de 2006. 
te, remetendo à legitimidade conferida pela carga ou peso levantado, aspecto que ganha importância, sobretudo, entre os homens, sendo muito provavelmente mais um fator a reforçar a afirmação da masculinidade.

A maioria do público da Pequena Academia pertence à categoria das pessoas comuns, segundo a classificação de Sabino (2002). Ela engloba todos aqueles que não se enquadram nos demais estratos. Nesta instituição, os investimentos, de um modo geral, são mais baixos, muito provavelmente pelo público que a freqüenta ser composto em grande parte por estudantes de uma universidade pública e pessoas que, em geral, apresentam menor poder de consumo. Esse fato faz com que a exigência normativa do ambiente em relação aos corpos também seja mais baixa, compondo um clima mais "tranqüilo", mais "light", como explica um freqüentador:

Aqui é menos badalado, mas isso pode até ser interessante porque tem muita academia que você vai aí e é um desfile de modas, isso não é gostoso, você pode até ta participando ali, mas, sei lá, é mais legal onde o pessoal, sei lá, ta mais informado, o pessoal mais humilde, talvez, assim, aqui nesse sentido é legal, o pessoal, sabe, não é tanto...não quer tanto ostentar alguma coisa, entendeu. (Adriano, 21 anos, estudante de Administração).

Os alunos desta academia vestem roupas simples e não vimos nenhum com grande desenvolvimento muscular. Os rapazes usam tênis, camiseta ou regata e bermudas. As meninas quase sempre usam calças justas, compridas ou até a canela, e camisetas folgadas ou blusinhas sem mangas coladas ao corpo. São raras as que vestem mini-blusas, mostrando o abdômen: "A maioria é universitário (...), tudo ferrado, sem grana, sabe, a maioria vem lá com um tenizinho All Star, sabe, não é academia que vai com um Nike da vida. Assim, uma galera bem simples mesmo, sabe, roupas simples." (Tiago, professor estagiário).

Esta diferença entre o "clima" desta e de uma outra institui-

Movimento, Porto Alegre, v.12, n. 01, p. 133-152, janeiro/abril de 2006. 
ção fica explícita no comentário de uma aluna, quando compara as suas sensações ao freqüentar esta e uma academia de grande porte:

Aí eu malhei uns dias na [nome da academia] e... é muito caro, e também as pessoas, o comportamento das pessoas eu não gostei muito (...) Não sei, parece que as meninas vão lá pra desfilar, assim sabe, daí eu não sei, não me senti bem daí mesmo, num ambiente desses, eu vim aqui porque é mais sossegado.(...) parece que ta todo mundo querendo desfilar ou competir uma com a outra, assim, isso que eu senti lá (...) até em questão de, sei lá, “a marca da roupa que ela tá usando", entendeu, tudo, assim, e as meninas vão super produzidas lá pra academia...(...) preferi uma academia mais tranquiila. (Alice, 22 anos, estudante de nutrição).

Todavia, por mais amenas que sejam as exigências e os investimentos na corpolatria, de nenhum modo esta academia perde a característica panóptica e disciplinar, no sentido que propõe Foucault $(1987,1999)$, ou permite qualquer desleixo em relação à gestualidade e aparência adequadas. Quem está naquele ambiente sabe que será visto, contemplado, analisado minuciosamente e, certamente, poderá agir na mesma direção, mas em sentido oposto.

Estas considerações permitem compreender as academias como espaços que representam o hiperdesenvolvimento do olhar em detrimento de outros sentidos, um fenômeno do mundo moderno, como aponta Le Breton (1995) e que Walter Benjamin (1997) identificou como centro da relação entre o humano e a sociedade contemporânea. Segundo Le Breton, uma série de transformações sociais decorrentes do progresso técnico - a exemplo da sofisticação dos meios de transporte como os ônibus e trens, que propiciaram a experiência das pessoas olharem-se por muito tempo sem lançarem mão da fala - levou a uma certa autonomia da visão em relação aos outros sentidos (LE BRETON, 1995).

Nas academias, o olhar - "sentido hegemônico da modernidade" (Idem, p.103) - parece atingir o ápice de sua eficiência, o que leva as pessoas a preocuparem-se com sua aparência

Movimento, Porto Alegre, v.12, n. 01, p. 133-152, janeiro/abril de 2006 
no interior do ambiente, no momento em que tomam consciência de que não é fácil escapar do sentido mais promíscuo, o mais contemporâneo, a poderosa visão.

É interessante notar que os imperativos de consumo dos corpos em parte variam de uma academia para outra e isso provavelmente corresponde às especificidades dos respectivos públicos que as freqüentam. Se isso nos faz escapar dos discursos totalizantes, também nos permite ver que os esquemas da indústria cultural alcançam alguma generalidade nos tratos com o corpo. Ao observarmos dois contextos algo diferenciados, verificamos similaridades que encontram no olhar o sentido mais aguçado, ainda que mediado pelas diferenças nas representações e expectativas de consumo. Isso se verá mais acentuado nas questões que passamos a discutir abaixo.

\section{Gênero e culto do corpo: os invólucros corporais idealizados por homens e mulheres}

Como já foi sugerido, no ambiente das academias certas regiões corporais adquirem diferentes estatutos de acordo com o gênero, o que será um determinante das configurações geográficas de cada espaço bem como dos olhares e preocupações individuais. A exemplo disso, são oferecidas aulas como o GAP (glúteos, pernas e abdominais) nas quais as partes anatômicas que mais preocupam as mulheres recebem máxima atenção. Na esteira dos ideais de beleza, verificamos que os discursos dos alunos de ambas as academias são muito semelhantes. As mulheres preocupam-se acima de tudo com a barriga - região onde qualquer resquício de gordura deve ser eliminado - com o volume dos seios, com a hipertrofia e delineamento das coxas, das pernas e, principalmente, das nádegas. Além disso, têm cuidados especiais com outros itens da aparência, como pele, cabelos, unhas etc: "Uma barriga sarada, uma perna, assim, bem torneada, um bumbum durinho, em pezinho, um seio bonito, um cabelo bem tratado, uma pele homo-

Movimento, Porto Alegre, v.12, n. 01, p. 133-152, janeiro/abril de 2006. 
gênea, não manchada.” (Patrícia, 25 anos, estudante).

Sabino (2000) sugere que as mulheres incorporam os requisitos de beleza a partir do ponto de vista masculino, determinando seus investimentos nos segmentos corporais mais admirados pelos homens. Por outro lado, suas exigências físicas para o sexo oposto, segundo nos disseram as depoentes, correspondem basicamente a um homem com pouca gordura abdominal, com músculos desenvolvidos e bem delineados; porém, manifestam aversão aos tipos exageradamente musculosos.

Ah, eu acho bonito o abdômen, assim, mais malhado. Eu gosto de homem grande, assim, com ombro mais largo, mas não muito, muito malhado, igual aqui, aqui assim...[mostrava o músculo trapézio]... aqui eu acho feio. Eu acho bonito homem grande, assim, mas também não muito, muito malhado eu acho feio, mas não sei também...mais eu acho que é o abdômen e o ombro largo assim... (Alice, 22 anos, estudante de Nutrição).

Os homens, por sua vez, almejam, sobretudo, aumentar o volume muscular - principalmente o dos membros superiores - e diminuir o percentual de gordura. Indo ao encontro do que afirma Sabino (2000), exercitam-se para si mesmos e para adquirirem prestígio entre os próprios homens, uma vez que, segundo essa dinâmica, "conquistar as mulheres nas academias é consequiência da aquisição desse status" (p. 100). Um aluno da Pequena Academia comenta: "Altura... pra mim eu queria ser mais alto, eu acho que, assim, $1,80 \mathrm{~m}$ eu acho que é uma altura ideal, assim, o cara...pô, já tem uma altura boa. Acho a questão de caixa, assim, caixa torácica,...braço...eu acho legal, o peito eu acho...." (Cláudio, 18 anos, estudante de Engenharia Mecânica).

Em suas considerações sobre o ideal de beleza física para uma mulher, os homens exaltam o corpo esbelto, com curvas "perfeitas", deixando explícita, algumas vezes, uma aversão à gordura corporal:

Movimento, Porto Alegre, v.12, n. 01, p. 133-152, janeiro/abril de 2006 
Em mulher, guria, assim...pra mim desde que não seja gorda e, sendo magrinha, não precisa ser gostooosa, assim. Não precisa ser aquelas que a galera considera...não ter um corpo, assim, "ah que corpão!". Mas assim, ter um rostinho que o cara...que eu gosto, assim...O corpo, pra mim...impõe só em questão de ser gorda ou magra. (Cláudio, 18 anos, estudante de Engenharia Mecânica).

É interessante observar a maneira com que certos padrões construídos pela cultura do corpo "ideal" ganham ares de "naturalidade" e de "normalidade", de modo que os informantes justificam seus argumentos lançando mão de um suposto "padrão cultural brasileiro" segundo o qual - numa "atualização" algo perversa do ideário de Gilberto Freyre - a "bunda" é considerada indiscutível elemento a disparar a atração pelo corpo feminino. Esse fetichismo ganha colorações "naturalistas" quando é justificado por meio de argumentos que remetem ao "instinto masculino" a preferência em relação às formas corporais de uma mulher: "Eu sou como brasileiro, 99.9 [\%] é bunda, uma mulher tem que ter bunda boa...[risos]...a fantasia eu acho que é pra esse lado (...) peito nem tanto, mas a bunda é...é fatal. (...) Eu e $99 \%$ dos brasileiros...[risos]...”.( Flávio, 45 anos, médico).

As declarações dos professores da Pequena e da Grande Academia, respectivamente, confirmam os diferentes investimentos no capital representado pelo corpo:

Sei de meninas que colocaram silicone, por exemplo...de lipo, não. (...) eu conheço duas...é porque dá pra notar que é muito desproporcional. (...) A amiga comentou.(...) sem perguntar, sabe... a gente tava conversando "ah porque a fulana lá, tá vendo lá oh, colocou silicone, não sei o que lá", sabe...conversa de bate-papo... (Tiago, professor estagiário).

Lipo?...aqui tem bastaaante, muuuita! Silicone então...[risos]...sem comentários! (...) Bastante, tem muito. Tem umas que você acha que não tem e tem. (...) elas falam: “fiz lipo aqui!'...tem umas que falam: "ai, eu fiz lipo, mas não conta pra ninguém”! Aî

Movimento, Porto Alegre, v.12, n. 01, p. 133-152, janeiro/abril de 2006 
tudo bem, eu não conto pra ninguém. (Flávia, professora).

Em outro momento a professora apenas citada resume em poucas palavras, e de modo interessante, a maneira como se sucedem os investimentos corporais na Grande Academia. A mensagem subliminar parece ser: A beleza é um conjunto de bens que podem ser adquiridos, e o grau de embelezamento parece ser diretamente proporcional ao poderio financeiro de cada um: "As mulheres e as meninas fazem de tudo porque que têm dinheiro...fazem dieta, exercícios, quem pode faz lipo, bota silicone, faz drenagem linfática... E os meninos, a maioria faz dieta...tomam anabolizantes e malham." (Flávia, professora).

Por outro lado, nas palavras de uma aluna da Pequena Academia vale notar a sensação de que seus investimentos são baixos, e que "deveriam" ser maiores:

Eu não sou de fazer tratamento estético, essas coisas eu não faço nada. (...) muito pouco...muito pouco, eu deveria fazer bem mais, eu faço bem pouco, assim. Eu só tiro tempo pra fazer essas coisas mesmo é no fim do ano, quando eu vou pra casa, assim...aí, mas durante, assim, no dia-a-dia eu não faço. (grifos nossos). (Bruna, 21 anos, estudante de Farmácia).

\section{Das (de)formações subjetivas à fluidez humana}

No complexo contexto do que podemos denominar "práticas do eu", a busca por uma adequação aos padrões corporais transcende o simples contentamento diante do espelho proporcionado por um retoque na silhueta. Muito mais do que isso, impele o indivíduo a uma (re)configuração identitária. Em um momento histórico ímpar como o que vivemos - no qual o corpo é entronizado como o bem supremo, condição que outrora se reivindicava para a "alma" - as transformações somáticas imputam uma nova maneira de pensar a si mesmo, levando, talvez, a uma transfiguração dos próprios sentimentos e emoções (SANT'ANNA, 2000).

Movimento, Porto Alegre, v.12, n. 01, p. 133-152, janeiro/abril de 2006. 
Nesta ordem cultural estruturada na sociedade do consumo, agregar valor ao corpo haverá de implicar, portanto, em uma vida vista como "melhor", com mais sucesso e felicidade (dois imperativos morais contemporâneos) e envolvendo um incremento incorporado que englobe desde o mercado de trabalho até o sexual. Nesse contexto, do mesmo modo que uma empresa privilegia um indivíduo de "boa aparência" para ocupar um posto de trabalho, uma linda mulher há de desejar um correspondente na forma física para um envolvimento afetivo.

Quem tá solteiro, tá no mercado, então quer dizer, você tem que estar disponível, e disponível hoje em dia é uma cobrança, tanto de um lado quanto do outro, porque uma mulher não vai sair...uma mulher que põe silicone e faz uma lipoaspiração e bota botox não vai querer pegar um cara barrigudo de 45 anos, ela vai querer um cara do padrão dela. Então quer dizer, o mercado acaba sendo violento em relação a esse tipo de coisa. Essa cultura do estético é uma cultura muito pesada (...). (grifos nossos) (Flávio, 45 anos, médico).

Fraga (2000), argumenta a respeito dos significados que envolvem a extrema valorização da forma física hodiernamente, num processo que tem por finalidade a produção de "anatomias de consumo". Portanto, desde que se tenha intenção e aporte financeiro, o corpo pode ser modificado a qualquer momento, inúmeros acessórios podem ser a ele incorporados e as novas formas corporais são compradas como um presente a ser entregue em um dia especial: "Meu sonho é botar silicone, se Deus quiser eu vou botar agora. (...) tipo se meu pai chegar e falar: 'ah, eu te dou agora', eu faço, mas não sei se ele vai falar isso agora ou se ele vai preferir que eu ponha em março. (Fernanda, 20 anos, estudante de Administração e Marketing).

No entanto, tornar-se "idealmente" belo não é o bastante, afinal este novo indivíduo que se apresenta deve identificar-se com seus iguais, ou pode ser confundido com um ser inferior, pois,

Movimento, Porto Alegre, v.12, n. 01, p. 133-152, janeiro/abril de 2006. 
como afirma Goffman (1988, p.58), "a identidade social daqueles com quem o indivíduo está acompanhado pode ser usada como fonte de informação sobre a sua própria identidade social." Uma aluna entrevistada explicita esta questão: "Eu tenho até amigas mais...[risos]... Mas assim, eu prefiro me importar mais com uma pessoa legal, mas só que tem essas coisas, você vai sair com uma pessoa, daí você vai sair com a feinha, daí vai...entendeu, vai atrapalhar, ou vai chamar menos a atenção, coisas assim, tem... (Alice, 22 anos, estudante de Nutrição).

Os exemplos de dois jovens estudantes, por sua vez, ilustram as novas relações que emergem na sociedade da imagem:

É...é até ruim falar, mas é verdade, tá associada a um monte de coisas. Tu vai procurar um emprego eles vão querer escolher o mais bonitinho, lógico que também pra paquerar, também, lógico, você não conhece a pessoa, a primeira coisa que você vai olhar é o quê?, a pessoa mais bonita, não é? (...) assim oh, eu tenho bastante amigo homem, então eu já percebi esse negócio de mulher assim, eu tenho uma amiga: "ah...não, não leva essa tua amiga, tua amiga feinha não leva, leva só as amigas gatas pra sair", entendeu?, um monte de coisas assim. (...) entendeu?...assim, ah vai dar carona? 'Ah não, mas tua amiga é gata? Se for feia eu não quero dar carona pra ela' ...[risos]...uma coisa assim. (Alice, 22 anos, estudante de Nutrição).

Assim, quem não tem cão, caça com gato, sabe? Por exemplo, quando eu era mais magro, não era por isso que eu deixava de ter os meus relacionamentos. Sou mais, sei lá, tô mais forte agora, com mais massa muscular, não vou dizer que...é aquela coisa, digamos, quando eu era magro eu acabava ficando com pessoas que gostavam...porque tem, eu noto, assim, muita mulher que não gosta de cara musculoso, assim, exageradamente, e muitas gostam. Eu, como não sou nem um, nem outro, tô ali, uns 45, nem 8 , nem 80, sabe, eu tô...pra mim ta me sendo útil, eu tô sabendo aproveitar essa minha nova condição. (grifos nossos). (Adriano, 21 anos, estudante de Administração).

Movimento, Porto Alegre, v.12, n. 01, p. 133-152, janeiro/abril de 2006. 
Os trechos acima podem apresentar aquilo que Adorno (1995, p. 130) chamou de consciência coisificada, o processo que corresponde, no plano intelectual, à reificação já encontrada nos ardis da indústria cultural: "No começo as pessoas desse tipo se tornam por assim dizer iguais a coisas. Em seguida, na medida em que o conseguem, tornam os outros iguais a coisas." Fetichizadas como coisas, as pessoas, assim como as partes de seus corpos, ocupam lugar no mercado, valorizam-se, vendem-se, são compradas ou trocadas como objetos úteis que logo em seguida podem ser descartados. No contexto das relações afetivas - que contemporaneamente vêm a compor o arcabouço social das relações de troca - os sujeitos postam-se diante da "frígida inatingibilidade do ser amado". Na busca de parceiros "mais bonitos" ou de melhor performance, cada um tenta inutilmente satisfazer o desejo insaciável de prazeres que não podem/devem, de fato, ser fruídos (ADORNO, 1992).

O adjetivo "belo" passa a ser empregado superficialmente na admiração do outro na medida em que essa afeição fica subjugada à sua adoração como um corpo reduzido a objeto. Essa exaltação do corpo coaduna-se com a valorização mercadológica de outros tantos produtos-fetiches, quando então a proporção dos investimentos que se faz em cada um deles irá indicar se são mais ou menos valiosos, regidos que são pelo princípio da troca de equivalentes: "À qualidade de cada um dos incontáveis automóveis que nas noites de domingo retornam a Nova York, corresponde com exatidão a beleza da moça que nele está sentada." (ADORNO, 1992, p. 147).

Ainda nesse sentido, e para finalizar, vale citar novamente Adorno (1992) que nos faz refletir sobre a pérfida crença da sociedade burguesa no amor enquanto um sentimento involuntário, na falsa imediatidade do sentimento, trama localizada também nas amarras dos imperativos que dizem sobre como dever ser homem ou ser mulher. Com isso, o autor chama a atenção para a necessidade da mediação dos sentimentos, sem a qual tornamo-nos sub-

Movimento, Porto Alegre, v.12, n. 01, p. 133-152, janeiro/abril de 2006. 
missos às inverdades que circundam entre os interesses da sociedade administrada:

Só ama quem tem a força para persistir no amor. Quando a vantagem social, sublimada, preforma o impulso sexual, usando mil nuances do que é sancionado pela ordem para tornar espontaneamente atraente ora esta pessoa, ora aquela, a inclinação, uma vez concebida, contrapõem-se a isso, na medida em que persiste mesmo quando a força da pressão social - antes de toda intriga, de que ela depois se serve regularmente - não o quer. (...) o amor que, sob a aparência da espontaneidade irrefletida e orgulhoso de sua pretensa sinceridade, se entrega por completo ao que acredita ser a voz do coração e foge no momento em que crê não ouvir mais aquela voz, é nessa independência soberana justamente o instrumento da sociedade. De maneira passiva, sem saber, ele registra os números que vão saindo da roleta dos interesses. Ao trair o ser amado, trai a si mesmo. A ordem da felicidade dada pela sociedade é um instrumento da não liberdade (...) (Idem, p. 151).

\footnotetext{
"Sarados" and "Gostosas" among some Others: Aspects of masculine and feminine Body Education in fitness centres

Abstract: This paper presents results of a six months research in two fitness centers in Florianópolis. The approaches - orientated by the contemporary phenomenon of the cult of body show up that the ascetic racing to the idealized body involves a praise/contempt of certain body segments and symbolic and materials borders that influence men and women in their choosing of different practices. The gender question is closely linked with the geographic spaces and the different hierarchies of corporal image. The results suggest the fluidity of human relations and carry the reflection to the possibility of subject vanishing.

Key words: Body. Gender. Subjectivity. Cult of the Body. Culture Industry.
} 


\begin{abstract}
"Sarados" y "Gostosas" entre algunos otros: aspectos de la educación de los cuerpos masculinos y femeninos en gimnasios

Resumen: El trabajo presenta resultados de una pesquisa desarrollada durante seis meses en dos gimnasios localizados en Florianópolis. Las investigaciones - orientadas por el fenómeno contemporáneo pelo fenómeno del culto al cuerpo - apuntan que la carrera ascética por la condición física idealizada supone la exaltación y el desprecio por ciertas regiones corporales, además de fronteras simbólicas y materiales que influencian hombres y mujeres al escogieren diferentes prácticas. Está conectada a la cuestión de género la geografía de estos espacios y las diferencias en las jerarquías pautadas en la imagen corporal. Los resultados sugieren una fluidez en las relaciones humanas e hacen pensar en un posible eclipse del sujeto.

Palabras-clave: Cuerpo. Género. Subjetividad. Culto al Cuerpo. Industria Cultural.
\end{abstract}

\title{
REFERÊNCIAS
}

ADORNO, T. W. Minima Moralia. São Paulo: Ática, 1992.

Educação e emancipação. Petrópolis, Vozes, 1995.

; HORKHEIMER, M. Dialektik der Aufklärung. In: ADORNO, T. W. Gesammelte Schriften 3. Suhrkamp: Frankfurt am Main, 1997.

BENJAMIM, W. Charles Baudelaire. Frankfurt am Main: Suhrkamp, 1997.

FOUCAULT, M. Vigiar e punir. Petrópolis: Vozes, 1987.

Em defesa da sociedade. São Paulo: Paz e Terra, 1999.

FRAGA, A. B. Anatomias de consumo: investimentos na musculatura feminina. Educação \& Realidade, vol. 25, n. 2, jul/dez 2000.

GOFFMAN, E. Estigma. Rio de Janeiro: Guanabara, 1988.

Movimento, Porto Alegre, v.12, n. 01, p. 133-152, janeiro/abril de 2006. 
LE BRETON, D. Antropologia del cuerpo y modernidad. Buenos Aires: Nueva Visión, 1995.

SABINO, C. Anabolizantes: drogas de Apolo. In: GOLDENBERG, M. (Org.): Nu \& vestido. Rio de Janeiro: Record, 2002. p.139-188.

SABINO, C. Musculação: expansão e manutenção da masculinidade. In: GOLDENBERG, M. (Org.): Os novos desejos. Rio de Janeiro: Record, 2000. p.61-103.

SANT'NNA, D. B. As infinitas descobertas do corpo. Cadernos Pagu, Campinas, n. 14,2000 , p. $235-249$.

VELHO, G. Subjetividade e sociedade: uma experiência de geração. Rio de Janeiro: Zahar, 1986.

Recebido em: 30/11/2005

Alexandre Fernandes Vaz MEN/CED/UFSC - Campus Universitário Caixa Postal 476

88040-900 - Florianópolis - SC alexfvaz@uol.com.br

Movimento, Porto Alegre, v.12, n. 01, p. 133-152, janeiro/abril de 2006. 